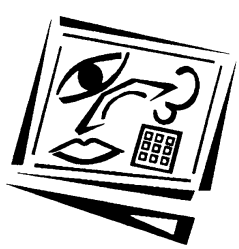

\title{
A review of podcasting in higher education: Its influence on the traditional lecture
}

Oliver McGarr

University of Limerick

\begin{abstract}
This paper examines the possible influence of podcasting on the traditional lecture in higher education. Firstly, it explores some of the benefits and limitations of the lecture as one of the dominant forms of teaching in higher education. The review then moves to explore the emergence of podcasting in education and the purpose of its use, before examining recent relevant literature about podcasting for supporting, enhancing, and indeed replacing the traditional lecture. The review identifies three broad types of use of podcasting: substitutional, supplementary and creative use. Podcasting appears to be most commonly used to provide recordings of past lectures to students for the purposes of review and revision (substitutional use). The second most common use was in providing additional material, often in the form of study guides and summary notes, to broaden and deepen students' understanding (supplementary use). The third and least common use reported in the literature involved the creation of student generated podcasts (creative use). The review examines three key questions: What are the educational uses of podcasting in teaching and learning in higher education? Can podcasting facilitate more flexible and mobile learning? In what ways will podcasting influence the traditional lecture? These questions are discussed in the final section of the paper, with reference to future policies and practices.
\end{abstract}

\section{Introduction}

Podcasting refers to the distribution of audio/video files in digital format. These resources can be manually downloaded from the Internet or distributed automatically to subscribers. These files can be accessed directly from the desktop or transferred to a portable media device such as an MP3 player to be listened to 'on the go'. The term podcasting emerged from the use of Apple's portable audio player, the iPod. Despite the proliferation of a range of portable audio, and more recently video, players by other manufacturers, the term podcasting remains the term used to describe the broadcasting of all audio/video files across the Internet in this manner. Podcasting has seen significant growth in education in recent years driven by claims of its value in supporting mobile learning and enhancing the student's experience. In higher education, podcasts are used frequently to deliver information that was once the preserve of the traditional lecture. Given the potential of podcasts to distribute recorded video and audio across wide networks of learners, it is reasonable to ask what its impact on the traditional lecture will be. Higgins (2003) notes that teachers often adopt innovations without always being able to understand their full implications for teaching and learning. Will it diminish the value and significance given to the traditional lecture? How will podcasting influence the traditional lecture in higher education? Through a review of recent literature, this paper explores the current use of podcasting in higher education in relation to the traditional lecture. This review aims to examine three key questions: 
- What are its educational uses in teaching and learning in higher education?

- Can podcasting facilitate more flexible and mobile learning?

- In what ways will podcasting influence the traditional lecture?

Before examining specific literature related to the use of podcasting, the benefits and limitations of the traditional lecture will be examined. Following this review, the key questions are revisited and discussed.

\title{
Examining the traditional lecture
}

According to Edwards, Smith and Webb (2001) lecturing is the main teaching method used in universities. They note that its dominance has influenced the very architecture of the teaching spaces used with fixed point podiums and tiered seating for large numbers of students. Such is its centrality in university teaching the term lecture is used synonymously with teaching. Behr (1988) notes that the term lecturer is preferred by most academic staff to the term of teacher. The origins of the lecture can be traced back over two millennia. Kozma, Belle and Williams (1978) note that its evolution as the main instructional system in European universities emerged in medieval times as the most effective method of transferring information stored in expensive and rare books to large groups of students. Today the lecture remains the most common form of communication in universities:

\begin{abstract}
... the established routines that treat lectures as the main medium for communication and education are still strong. Lectures as educational episodes are still likely to represent among the most robust methodologies used by institutions to educate their students. (Moore, Armstrong \& Pearson, 2008, p. 18)
\end{abstract}

Forty years ago Fitzgerald (1968) asked, 'Is there any point in the lecture as a form of university teaching? After all, if information is what the students want, then surely a well stocked library is the answer.' (p. 11). The question has even more relevance today in a digitally rich society with instant access to information in many forms. Yet despite the emergence of various technologies over the centuries, there are numerous reasons why the lecture has remained. Kozma et al. (1978) argue that from an economic point of view the lecture is relatively inexpensive, they also note that it has survived the competition of technologies such as television and film because of the relatively low preparation time in comparison to other media.

There are several educational advantages to lectures, particularly if it is seen as more than a method of information delivery. Edwards et al. (2001) note that while poor lectures can leave students bored and frustrated, good lectures can inspire. Dolnicar (2005) claims that effective lectures can provide the excitement of intellectual discovery through the presentation of challenging and provocative ideas. She further adds that the lecturer can relate the lecture content to his/her students' prior knowledge and relate it to real life examples, thus making the knowledge more meaningful. The lecture can also be seen as a way of opening up a subject to a student helping them to find their way through a large body of complex knowledge and providing the most up to date knowledge in a particular field (Laing, 1968). Moore et al. (2008) note that lectures:

... provide important signposts to students, that explain the rules of engagement that many of them find it otherwise difficult to learn, and that help them to understand the areas and tasks that they need to focus on most in order to navigate their learning experiences more successfully (p. 17) 
Yet, despite these benefits there are drawbacks to the lecture as a form of teaching. Williams and Fardon (2007) argue that "the role and effectiveness of the lecture in higher education is a highly debated topic" (p. 1085). Isaacs (1989) observes that lecturing is often characterised as the transfer of the lecturer's notes to the students' notepads without any thinking or processing of the information. This low level of engagement in lectures, according to Kozma et al. (1978), encourages intellectual passivity. This view is supported by Black (2005) who believes that the over-emphasis on the teacher rather than the students contributes to the student's isolation and disengagement from the lecture, which discourages critical thinking and analysis of the content. Similarly, Gibbs, Habeshaw and Habeshaw (1987) believe that lectures induce a passive, reproductive mental set in students. Coupled with these problems is the 'shift towards pragmatism among students' (Dolnicar, 2005, p. 103), who see the lecture as simply a form of information transfer. Research by Moore et al. (2008) into the reasons for lecture non-attendance of 230 undergraduate business students in an Irish university, found that the students;
... do not articulate a sense of obligation to attend lectures, despite the messages, assumptions and convictions that faculty members may share about the importance of such attendance. Among this sample of students, at the very least, occasional lecture absenteeism is the norm and, for many, absenteeism is a relatively regular occurrence. (p.20)

The generally passive role of students in most lectures is at odds with current thinking, which emphasises the need for more student centred learning strategies. Tormey and Henchy (2008) claim that traditional lectures take little account of this contemporary thinking. Over 20 years ago Gibbs et al. (1987) observed that, 'there is an accelerating trend in teaching methods in higher education away from teacher centred pedagogy towards learner centred approaches' (p. 11). However they also noted that this trend was restricted by resource constraints, and that in many institutions large lecture classes remain, because of their resource efficiency rather than their effectiveness.

Despite the apparent immunity of the lecture to changes over the decades, the development of digital technologies is opening up many possibilities. The use of podcasting as a method to enhance the lecture has emerged as growing technology. The following section will examine this recent interest.

\section{Recent interest in podcasting and its proposed benefits}

Much that is written about podcasting refers to its ability to enhance convenience, flexibility and accessibility to learning (Frydenberg, 2006; Nathan \& Chan, 2007). It appears that when one examines the purpose behind the use of podcasting, it falls into three broad categories: enhancing the flexibility of learning, increasing accessibility to learning (particularly in relation to enabling mobile access) and enhancing the student's learning experience (particularly in on campus courses through the use of more blended learning experiences).

\section{Increasing flexibility}

The distribution of course material in video and audio formats, to provide greater flexibility to learners, has been a common characteristic of distance learning programs for a number of years. Digital technologies have enhanced this process through the use of digital audio and video recordings that can be distributed across the Internet directly to learners' desktops. More recently, students can subscribe to automatic 
downloads of new material as it becomes available, so it can be accessed by the student in their own time and place. This form of automatic distribution of material certainly increases the learner's flexibility in accessing the course content.

\title{
Increasing accessibility
}

The ability to access this material on portable devices such as MP3 players can enable more mobile access to the material. Evans (2008) argues that the increasing demands on modern learners' time means that they are often forced to study when the opportunity arises, this may be on the bus, train or car, at evening or weekends or during lunch breaks. These demands bring with them the need for portable technologies that enable them to transport their learning materials to access when they can. This 'mobile learning', or m-learning for short, is used widely in distance learning programs because of the relative ease in which the digital resources can be produced (Bongey, Cizadlo \& Kalnbach, 2006) and because they facilitate the needs of the learner and enhance their learning experience;

\begin{abstract}
$\mathrm{m}$-Learning is a natural match for distance education, since it has the potential to fit in with the unique work-style requirements of the mobile workforce, who form a large proportion of current and potential distance learners ... by harnessing the idle moments they have in their day waiting or travelling on public transport, allowing them to undertake learning in conjunction with other tasks, or when on the move for extended periods of time, such as during business trips. Many of them are

'continuously connected' by mobile phones, laptops and hand-held devices. (Lee \& Chan, 2007, p. 202)
\end{abstract}

Yet, despite the perceived value of the role of podcasting in facilitating m-learning, Lee and Chan (2007) question this assertion. In examining these trends they ask 'Is mlearning nothing more than the new flavour of the month? Does it actually have anything new to offer us in the way of improving and/or enhancing the way we teach and learn?' (p. 203). Questions linger in relation to its true educational value, the ways it can be best utilised to support teaching and learning, and its affect on attendance and student engagement.

\section{Enhancing learning}

As well as its increased use in distance education programs, podcasting has also become popular with on campus courses. Kennedy, Judd, Churchward, Gray and Krause (2008) note that the use of podcasts in education is gaining acceptance rapidly. They further add that the degree to which students are using new and emerging technologies in their daily lives opens up several opportunities to embed these technologies into the university experience. Similarly, Harris and Park (2008) note that the increasing use of podcasting in education has the potential to significantly change the teaching and learning experience of students. They note:

\footnotetext{
Podcasting is being utilised not only to provide a repeat or summary of a lecture given but also to provide timely academic material such as law-related news to students. Such usages could create the relationship that is based on continuous communication and interaction between teachers and students by having students engage in academic debate and in accessing timely academic research (p. 549)
}

Copley (2007) notes that a number of universities have begun to use podcasts to 'deliver supplementary lecture materials for campus-based students' (p.388). He claims that the most common use of podcasting involves the distribution of lecture 
recordings for students to review and revise. This approach he argues, is not too dissimilar to the distribution of lecture notes in PowerPoint or similar formats to students. As well as offering greater convenience, connection and control for the learner, Williams and Fardon (2007) argue that the opportunity to replay and review past lectures through podcasting aids revision and comprehension. Lazzari and Betella (2007) have also noted this trend towards the use of podcasting to distribute learning materials, but they also note that the literature is not well-supplied with examples of case studies and evaluations of their use.

Having briefly examined the proposed advantages in using podcasts in education, it is important to examine studies of its actual use, in order to gain an insight into the reality of its use and attempt to answer the three questions outlined in the introduction section.

\section{Reviewing the literature on podcasting}

Being a recent technology, it is perhaps understandable that research into the area of podcasting in education is limited. Lazzari (2008) notes that there remains a paucity of research, case studies and evaluations of the use of podcasting in education. Those that exist, according to him, are mostly surveys into users' acceptance of the innovation rather than studies examining its effect on the students' learning. Others appear to focus on the technical aspects of the innovation, for example audio or video quality and issues of bandwidth (Lazzari \& Betella, 2007). Yet there are a number of studies that provide an insight into some of the pertinent issues relating to its use in higher education and its influence on the traditional lecture.

Lee and Chan (2007) report a study in which podcasting was used to deliver supplementary material to distance learning students in an Australian university, their research aiming to examine the level of uptake, the perceived value of the podcasts and the students' preferred way of using the podcasts. This case study used podcasts structured as short 3-5 minute talkback radio style segments. The research employed an online survey distributed to all 39 students on completion of the program. Following the survey, a small random sample of students were selected for semistructured interviews. Of the 18 respondents to the survey all reported downloading at least 8 of the 9 available podcasts, and $89 \%$ of them reported listening to at least three of the podcasts multiple times. Unlike the uses reported in the literature, which claims that students can access and learn from the material on the go, the students in the study preferred to listen to the podcasts using a computer at home during a dedicated study time. The authors further note that;

It was evident from most of the interviewees' responses that they did not multitask their listening of the podcasts with other tasks because they treated it as a learning activity that formed part of formal, deliberate study efforts demanding undivided attention and concentration within a designated study location (usually in the home). (Lee \& Chan 2007, p. 211)

They further argue that the usage reported in their research is at odds with the views of m-learning portrayed in the literature. They add that further research into the issue of multitasking is required since the concept of m-learning is based on the premise that the learner has the capacity to deal with the cognitive load of focusing on the audio podcast and attending to other tasks in parallel. This finding is supported by a study by Evans (2008) into the use of podcasts by 196 undergraduate business and 
management students in a United Kingdom university. The study involved the use of three revision podcasts provided to the students on completion of a course on information and communications technology but prior to the examination. In order to access the final podcast, participants were required to complete an online questionnaire that explored their experience and attitudes towards the various technologies used to assist the delivery of the course. Similar to Lee and Chan's (2007) study, $80 \%$ of the students in Evan's (2008) study listened to the podcasts on a PC rather than a mobile device. While participants of the study were not asked whether they owned a portable media device to play the podcasts, a survey of level-two students in the same institution revealed that $70-80 \%$ of the students had portable media devices. This suggests therefore that a similar level of ownership was likely in the participating group. In addition to how they used the podcasts, the students also reported finding them useful as part of their revision. In light of these findings Evans (2008) notes that:

\footnotetext{
This suggests that podcasting can fill an important needs gap by allowing learners to continue the learning activities when it might not normally be possible. However, podcasts did not appear to offer much in the way of facilitating multi-tasking, with most people claiming that they did not undertake any other activities whilst listening to podcasts. (p. 495)
}

A study by Huntsberger and Stavitsky (2007) into the use of podcasting in a United States university found similar types of use. The research, which aimed to explore students attitudes towards podcasting and how they used it, investigated five course revision podcasts of 15 to 28 minutes in duration, providing chapter summaries and syntheses of course material at stages during the program. The podcasts were provided to 249 students of an introductory journalism course. Students were invited to complete an online survey and contribute comments and opinions to an online discussion forum. The survey obtained 209 responses from 249 students $(89 \%$; the authors note that students were offered extra credit towards their final course grade as an incentive to participate). The research found that $87 \%$ of the respondents listened to all podcasts at least once and that $91 \%$ of the respondents accessed the podcasts "during their regular study sessions" (p. 403), rather than while engaged in some other activity. While students found the initiative beneficial, the authors note that $40 \%$ of the students used the podcasts as a replacement to the textbook rather than additional revision material to supplement it. In light of this finding the authors noted that:

the instructor is faced with divergent approaches: rethinking how to make the podcasts complement the readings without providing enough detail to make the text seem unnecessary, or conceptualising the podcasts as a substitute for the text as, in effect, an aural packet of readings, augmented perhaps by online sources. (p. 407)

Willams and Fardon (2007) conducted a study into how and why students used portable media players to watch or listen to lecture recordings in an Australian university. Their research involved the use of an anonymous online student survey and focus groups. A total of 1,074 responses were received from the online survey, however the authors do not highlight the number of focus groups conducted or the response rate of the online survey. The university provided recorded lectures in various formats, streamed, downloadable and podcasted. As with the previously cited studies, the recorded lectures were seen as helpful. The study found that $71 \%$ of the respondents indicated using the lectures for revision and review, while $47 \%$ of respondents used them because of timetable clashes, and $43 \%$ because of work and family commitments. About $28 \%$ indicated they accessed the recordings as they 
preferred them to the actual lectures. The authors note that, unlike other studies in the literature, the portability of the recording format was seen as important by a high proportion of the surveyed students. The reason for this, they suggest, is the nature of the university which tends to have a very high proportion of students that commute to the campus rather than living on or near it. The ease of access to MP3 files rather than streamed audio was also suggested by the authors as a possible reason for this preference.

The students' preference for the 'real' lecture, as opposed to the recorded podcast, was also apparent in a study by Copley (2007) into the use of supplementary material delivered through video and audio podcasts to 283 undergraduate and postgraduate science students in the United Kingdom. Using an online survey as the primary form of data collection and through analysis of the students' download patterns, Copley found that students tended to use the podcasts for revision purposes rather than a replacement for the lecture;

Patterns of downloads in time show clear peaks immediately after the podcasts were made available, followed by sustained low-level download activity throughout the semester and additional peaks immediately before exams or assessments (p. 390)

As with the previous studies there was a high level of enthusiasm for the future use of podcasts with $93 \%$ of the respondents indicating that they would like to see greater use of them. In line with previous studies referred to earlier, the study also found that $94 \%$ of the respondents who downloaded the audio podcasts played them mostly on a PC and that $87 \%$ who played the audio podcasts referred to lecture notes when reviewing them. Only $13 \%$ of the respondents listened to them while doing other things. Copley (2007) concludes that 'Very few students indicated that they used the podcasts in an mlearning context, reviewing their content while engaged in other tasks' (p. 398).

Not all examples report high levels of pupil interest. Lazzari (2008) conducted research into the use of podcasting to deliver supplementary recorded material to 47 students studying a course in multimedia communications at an Italian university. The 10-15 minute recordings ranged from discussions to syntheses of material covered. The research study analysed students' test scores, distributed surveys and collected data from student colloquia. The study found that students had a positive view of the use of podcasting as part of their learning but found 'a significant preference for notes rather than podcasts as a quick tool for revising' (p.5).

Bongey, Cizadlo and Kalnbach (2006) conducted research in a United States college into the use of recorded podcast lectures. Their research aimed to examine the effect of podcasts on student attendance, the students' preferred use of podcasts, and the students' perceptions of their academic impact. The research utilised observations, attendance records, server statistics and a survey distributed to the 246 participating biology students (response rate 67\%). The study found that the availability of the podcasts did not lead to declines in attendance, with $95 \%$ of students indicating that they did not attend class less often. This self reporting was supported by observations of attendance. While $70 \%$ of the survey respondents indicated that they had used the podcasting to improve their understanding of the course content, similar to the research by Lazzari (2008) referred to previously, $94 \%$ of the respondents indicated that they preferred the lecture over the podcast. The authors concluded that: 
All of these findings seem to indicate that students perceive the podcasts as really useful additional resources available to help them succeed in their courses rather than as a substitute for more traditional methods of learning. (Bongey et al., 2006, p. 362)

These findings concur with a study by Hove and Corcoran (2008) into the effect of lecture presentation availability on class attendance and academic performance. The research was conducted with 365 students studying an introductory course in psychology in a large Midwestern university in the United States. It found that the availability of recorded lectures for students "did not reveal significant differences in attendance rates" (p. 93). Comparing students' test scores with attendance among two groups of students, one with unlimited access to recorded lectures the other without access, the authors also noted that:

Our findings suggest that the supplemental class format was particularly useful for students with lower attendance, whereas among students with higher attendance, class format was not influential in determining course grades. (p. 93)

However, the authors noted that they viewed the study as a preliminary investigation and that further research is required to examine in more detail the causal relationship identified in their study.

While the studies referred to up to this point have focused on the instructor/teacher as the producer of podcasts, some studies have examined the creation of podcasts by students. Lazzari (2008), referred to previously, gave fulltime students in a multimedia communication program three course tasks which involved the development of their own podcasts. The first task involved the students in editing an audio file provided to them. In the second task the students had to record their own answers to the original questions in the first audio file and replace the original answers with their new recordings. The final and most challenging task, required students to work in small groups to prepare a podcast on one of the themes of the theoretical course studied. Lazzari concluded that:

... by data and observation we can say that podcasting design, recording, and editing spurred the development of reflective learning skills, stimulated students to go deep into the questions they had to face, and fostered positive collaborative behaviours, promoting the growth of students' collaborative learning skills. (p. 6)

Similarly, a study by Frydenberg (2006) into the use of student generated podcast summaries in a business college in the United States found that, while podcasting is useful in disseminating course information, its use becomes more beneficial when students are challenged to become creators of the material to be disseminated. Frydenberg noted that as well as developing critical thinking skills, students must also have a comprehensive understanding of the material in order to create the podcasts. The nature of the activity therefore leads to a very engaging and worthwhile learning experience.

\section{Issues emerging from the review of literature}

The exploration of the use of new and emerging technologies in education is an ongoing pursuit. Huff (1991) believes that this urge to use the latest technologies is understandable, even commendable, but he believes that their use should be grounded by sound educational goals rather than ambitious expectations. The educational use of podcasting has been accompanied by similar expectations, but what is the reality? The 
use of podcasting in education is a relatively recent innovation and much of the use reported in this review captures a time of exploration and experimentation. Yet this brief review has raised a number of issues which shed further light on its implications for policy and practice. In returning to the three questions several issues emerge.

\section{What are its educational uses in teaching and learning in higher education?}

Given the limitations of using podcasting to support 'mobile learning', and the students' preferences that emerge from the studies reviewed, what are the ways in which it can be used? The uses outlined in the previous studies point to three broad categories along a continuum of use: substitutional use, supplementary use and creative use. At a most basic level podcasting can be used as a substitute to the traditional lecture where students can access an entire recording of the lecture. While there is educational value in providing recordings of lectures for the purposes of revision and review, if used exclusively as a substitute for traditional lectures such use may further reinforce students as passive recipients of information.

Podcasting can also be used to provide supplementary material to assist learning. It appears that there is significantly more educational value to podcasts when used in this way. However, supplementary material can be in two very different forms. The first, and most common form, is their use in providing summaries or syntheses of course material, for example, summaries of lectures and syntheses of core readings. Primarily using podcasts to provide summaries of material covered previously can, like the substitutional use outlined above, add to the passivity of students and may ultimately encourage less engagement in traditional lectures. This was apparent in Huntsberger and Stavitsky's (2007) research, referred to above, where $40 \%$ of the students used the revision material supplied in the podcasts rather than reading the core texts. As well as providing revision and summary material, supplementary material can also be in the form of additional material which may broaden or deepen the student's understanding. This type of use can facilitate higher cognitive learning outcomes since the provision of supplementary material can provide students with alternative perspectives on content previously delivered or enable further and deeper exploration of topics.

The final and least frequently mentioned use of podcasts in education, is what could be described as creative use, wherein students become more engaged in the learning through constructing knowledge rather than simply receiving it. The student is required to have a deep level of knowledge of the subject matter if they are to successfully construct a suitable podcast, and therefore this type of uses challenges the student to critically examine the material they have been exposed to previously. This type of use can also develop students' ICT skills through the creation and manipulation of digital media. When provided as a group task, other important social skills, such as the student's ability to collaborate and participate effectively in a group, can be developed. Use of this student generated content can also facilitate peer learning and contribute to a supportive and constructive class environment. Lee et al. (2008) believe that 'the true potential of podcasting technology lies in its knowledge creation value, and its use as a vehicle for disseminating learner generated content' ( $p$. 504). Used in this way students can become knowledge creators rather than simply knowledge receivers. However, it must also be noted that the completed student summaries could be used as substitutes for deep learning by other students when distributed to the larger group of course participants. This spectrum of use is summarised in Figure 1. 


\section{Educational uses in supporting/enhancing the lecture}

\begin{tabular}{|c|c|c|c|}
\hline $\begin{array}{l}\text { Passive receivers } \\
\text { of information }\end{array}$ & & & $\begin{array}{l}\text { Active constructors } \\
\text { of knowledge }\end{array}$ \\
\hline Substitutional & \multicolumn{2}{|c|}{ Supplementary } & Creative \\
\hline $\begin{array}{l}\text { Receiving } \\
\text { complete lecture } \\
\text { recordings }\end{array}$ & $\begin{array}{l}\text { Accessing } \\
\text { summaries of } \\
\text { lectures and } \\
\text { course content }\end{array}$ & $\begin{array}{l}\text { Accessing } \\
\text { additional } \\
\text { learning } \\
\text { material }\end{array}$ & $\begin{array}{l}\text { Creating podcasts } \\
\text { to be distributed to } \\
\text { peers and other } \\
\text { learners }\end{array}$ \\
\hline
\end{tabular}

Figure 1: Educational uses of podcasting in supporting/enhancing the lecture

\section{Can podcasting facilitate more flexible and mobile learning?}

As outlined at the beginning of the paper, podcasting is commonly seen as a way of supporting m-learning since it enables learners to access course material on portable devices in any location. This opens up possibilities of accessing the material at opportune times such as during commuting. Yet the evidence from the research studies presented highlights that the majority of students did not access the material in this manner, and instead used it during designated study times when they had access to additional notes and texts. Following a literature review of m-learning by Lee and Chan (2007) they claimed that they were unable to locate research conducted into students' abilities to multitask their listening of podcasts with other activities. Laing and Wootton (2007), referring to the university of Wisconsin's guidelines on podcasting, note that an important pedagogical consideration in the use of podcasting is the nature of the content delivered:

The learner will probably be listening to your podcast whilst carrying out another task such as walking, sitting on a bus or exercising. Therefore, avoid dense complex material which is better covered in a lecture. (p. 8)

The level of concentration and processing that is required to deconstruct and understand information delivered appears to limit the use of podcasting in this mobile way, particularly its ability to deliver complex material. There appears to be a considerable difference between the anticipated use of podcasting in this mobile way and its actual use. Lee and Chan (2007) note that rhetoric, rather than actual research, is often used to justify the use of modern mobile technologies in education:

... educators and technologists must be wary about claims that new technologies and devices can be used for learning anyplace, anytime-pedagogical, technical, logistical, usability and social constraints must be given due consideration. (p. 215-216)

\section{In what ways will podcasting influence the traditional lecture?}

The effect of podcasting on the traditional lecture is ultimately dependent on how the traditional lecture is viewed. If seen as a mechanism to deliver information to a large audience of students, one could argue that a recorded lecture would be as effective. Lee, McLoughlin and Chan (2008) note that most use of podcasting is as a 'distribution 
mechanism to replace face to face teaching' (p. 517). A concern frequently expressed about this type of use is the potential effect on student attendance. Yet as a number of the studies have indicated, this does not appear to have a negative effect on student attendance. On the contrary, students appear to prefer the 'real' lecture (Hove \& Corcoran, 2008; Frydenberg, 2006; Bongey et al., 2006). Students' preference of the traditional lecture, and the limited impact on attendance when used in this way, suggests that its impact on the traditional lecture may be limited. There are a number of possible reasons, alluded to earlier, that may explain this. The lecture can be much more than the transfer of information. While at a very basic level it performs this function, it can also inspire and enthuse students. The lecturer's insight and knowledge of the subject area can also assist them in understanding the complex material and provide them with guidance through the topic (Moore et al, 2008). Seen in this way the lecture initiates and enhances the student's learning rather than being the learning experience.

In addition, the lecture is also a social event; students attend together and experience the speaker's opinions and perspectives. This shared experience can initiate debate and discussion among students that may not be possible when delivered in other ways.

\section{Conclusion}

In conclusion, podcasting has the potential to enhance learning, but the reason given to justify its use in education, namely as a tool to support mobile learning, does not appear to be apparent in the studies reviewed. Educators need to be cautious of the claims made in relation to new and emerging technologies, particularly in the assumptions made by proponents of the technologies. The development of future policies in institutions should be cognisant of the limitations of the technology in supporting a more mobile form of learning, since it appears to be used by students in a more traditional way to support and enhance their normal modes of study.

When used to enhance the students' learning experience, there are a number of issues that need to be considered. If used to provide access to records of previous lectures, or to provide summaries and syntheses of course material, careful consideration should be given to how the students should use the material. If seen as the primary source of material and learning by the students, this type of technology may diminish the students' learning experience. In this context, it is important to ensure that students possess the study skills needed to use the support material effectively.

As this review has highlighted, the use of podcasting can range along a spectrum, from being used as a substitute to the traditional lecture, to being used as a tool to enable student generated content. While podcasting has the potential to enhance the students' learning experience, it also can reinforce the worst aspects of the transmission model of learning. For this reason, future use of these technologies should be learner led, rather than technology led. Will they enhance or augment aspects of the students' experience, or will it be a technological solution in search of an educational problem? Future uses of the technology should be guided by sound educational goals that aim to improve the students' existing experience, rather than being guided by vague claims of revolutionising it.

Similar to many other educational technologies in the past, the ultimate use of podcasting and its influence on the traditional lecture may not be determined by the 
potential of the technology, but rather by the way in which it is perceived within the institution, by both teachers and students. Its use will be strongly influenced by the dominant pedagogies employed in these contexts.

\section{References}

Behr, A. (1988). Exploring the lecture method: An empirical study. Studies in Higher Education, 13 (2), 189-200.

Black, L. (2005). Dialogue in the lecture hall: Teacher-student communication and students' perceptions of their learning. Qualitative Research Reports in Communication, 6(1), 31-40.

Bongey S., Cizadlo, G. \& Kalnbach, L. (2006). Explorations in course-casting: Podcasts in higher education. Campus-Wide Information Systems, 23(5), 350-367.

Copley, J. (2007). Audio and video podcasts of lectures for campus-based students: Production and evaluation of student use. Innovations in Education and Teaching International, 44(4), 387399.

Dolnicar, S. (2005). Should we still lecture or just post examination questions on the web?: The nature of the shift towards pragmatism in undergraduate lecture attendance. Quality in Higher Education, 11(2), 103-115. [verified 30 May 2009] http:/ / ro.uow.edu.au/ commpapers/299/

Edwards, H., Smith, B. \& Webb, G. (2001). Introduction. In H. Edwards, B. Smith \& G. Webb (Eds), Lecturing: Case studies, experience and practice (pp. 1-10). London and Philadelphia: Kogan Page.

Evans, C. (2008). The effectiveness of m-learning in the form of podcast revision lectures in higher education. Computers \& Education, 50, 491-498.

Fitzgerald, P. (1968). The lecture: An Arts view. In D. Layton (Ed.), University teaching in transition (pp. 11-17). UK: Robert Cunningham and Sons.

Frydenberg, M. (2006). Principles and pedagogy: The two P's of podcasting in the information technology classroom. In Proceedings of the Information Systems Education Conference 2006, v23 (Dallas). [verified 30 May 2009] http:/ / proc.isecon.org/ 2006/3354/ISECON.2006.Frydenberg.pdf

Gibbs, G., Habeshaw, S. \& Habeshaw, T. (1987). Improving student learning during lectures. Medical Teacher, 9(1), 11-20.

Harris, H. \& Park, S. (2008). Educational usages of podcasting. British Journal of Educational Technology, 39(3), 548-551.

Higgins, A. (2003). On learning and teaching with technology: Principles and practices. In S. Naidu (Ed), Learning and teaching with technology (pp. 289-291). London: Kogan Page.

Hove, M. \& Corcoran, K. (2008). If you post it, will they come? Lecture availability in introductory psychology. Teaching of Psychology, 35(2), 91-95.

Huff, C. (1991). The myth of technological determinism in teaching and technology: The impact of unlimited information access on classroom teaching. Michigan: The Pieran Press, Ann Arbor.

Huntsberger, M. \& Stavitsky, A. (2006). The new "podagogy": Incorporating podcasting into journalism education. Journalism and Mass Communication Educator, 61(4), 397-410.

Isaacs, G. (1989). Lecture note-taking, learning and recall. Medical Teacher, 11(3), 295-302. 
Kennedy, G., Judd, T., Churchward, A., Gray, K. \& Krause, K. (2008). First year students' experiences with technology: Are they really digital natives? Australasian Journal of Educational Technology, 24(1), 108-122. http:/ / www.ascilite.org.au/ajet/ ajet24/ kennedy.html

Kozma, R., Belle, L. \& Williams, G. (1978). Instructional techniques in higher education. New Jersey: Educational Technology Publications.

Laing, A. (1968). The art of lecturing. In D. Layton (Ed), University teaching in transition (pp. 1834). UK: Robert Cunningham and Sons.

Laing, C. \& Wootton, A. (2007). Using podcasts in higher education. He@lth Information on the Internet, 60(1), 7-9. http: / / hii.rsmjournals.com/cgi/ reprint/60/1/7

Lazzari, M. (2008). Creative use of podcasting in higher education and its effect on competitive agency. Computers E Education, 52(1), 27-34.

Lazzari, M. \& Betella, A. (2007). Towards guidelines on educational podcasting quality. In M. Smith \& G. Salvendy (Eds), Human interface and the management of information. Lecture Notes in Computer Science (pp. 404-412). Heidelberg: Springer.

Lee, M. \& Chan, A. (2007). Pervasive, lifestyle-integrated mobile learning for distance learners: An analysis and unexpected results from a podcasting study. Open Learning: The Journal of Open and Distance Learning, 22(3), 201-218.

Lee, M., McLoughlin, C. \& Chan, A. (2008). Talk the talk: Learner-generated podcasts as catalysts for knowledge creation. British Journal of Educational Technology, 39(3), 501-521.

Moore, S., Armstrong, C. \& Pearson, J. (2008). Lecture absenteeism among students in higher education: A valuable route to understanding student motivation. Journal of Higher Education Policy and Management, 30(1), 15-24.

Nathan, P. \& Chan, A. (2007). Engaging undergraduates with podcasting in a business subject. In ICT: Providing choices for learners and learning. Proceedings ascilite Singapore 2007. http: / / www.ascilite.org.au/conferences/singapore07/ procs/nathan.pdf

Tormey, R. \& Henchy, D. (2008). Re-imagining the traditional lecture: An action research approach to teaching student teachers to 'do' philosophy. Teaching in Higher Education, 13(3), 303-314.

Williams, J. \& Fardon, M. (2007). Perpetual connectivity: Lecture recordings and portable media players. In ICT: Providing choices for learners and learning. Proceedings ascilite Singapore 2007. http: / / www.ascilite.org.au/conferences/ singapore07/ procs / williams-jo.pdf

Dr Oliver McGarr, Department of Education and Professional Studies Faculty of Education and Health Sciences, University of Limerick, Ireland. Email: oliver.mcgarr@ul.ie Web: http: / / www2.ul.ie/web/WWW/Faculties / Education_\%26_Health_Sciences/Departments/Education_and_Professional_Studies 